\title{
Continuous $n$-valerate formation from propionate and methanol in an anaerobic chain elongation open-culture bioreactor
}

\author{
Sanne M. de Smit ${ }^{\dagger}$, Kasper D. de Leeuw ${ }^{\dagger}$, Cees J. N. Buisman and David P. B. T. B. Strik ${ }^{*}$ (1)
}

\begin{abstract}
Background: Chain elongation forms a new platform technology for the circular production of biobased chemicals from renewable carbon and energy sources. This study aimed to develop a continuous methanol-based chain elongation process for the open-culture production of a new-generation biofuel precursor and potential platform chemical: $n$-valerate. Propionate was used as a substrate for chain elongation to $n$-valerate in an anaerobic open-culture bioreactor. In addition, the co-production of $n$ - and iso-butyrate in addition to $n$-valerate via, respectively, acetate and propionate elongation was investigated.

Results: $n$-Valerate was produced during batch and continuous experiments with a $\mathrm{pH}$ in the range $5.5-5.8$ and a hydraulic retention time of $95 \mathrm{~h}$. Decreasing the $\mathrm{pH}$ from 5.8 to 5.5 caused an increase of the selectivity for $n$-valerate formation (from 58 up to $70 \mathrm{wt} \%$ ) during methanol-based propionate elongation. $n$-Valerate and both $n$ - and isobutyrate were produced during simultaneous methanol-based elongation of propionate and acetate. Propionate was within the open-culture preferred over acetate as a substrate with 10-30\% more consumption. Increasing the methanol concentration in the influent (from 250 to 400 mM) resulted in a higher productivity (from 45 to 58 mmol C/L/ day), but a lower relative product selectivity (from 49 to $43 \mathrm{wt} \%$ ) of $n$-valerate. The addition of acetate as a substrate did not change the average $n$-valerate productivities. Within the continuous bioreactor experiments, 6 to 17 wt $\%$ of formed products was methane. The microbial community during all steady-states in both methanol-based elongation bioreactors was dominated by species related to Clostridium luticellarii and Candidatus Methanogranum. C. Iuticellarii is the main candidate for $n$-valerate formation from methanol and propionate.
\end{abstract}

Conclusions: $n$-Valerate was for the first time proven to be produced from propionate and methanol by an openculture bioreactor. Methanogenic activity can be inhibited by decreasing the $\mathrm{pH}$, and the $n$-valerate productivity can be improved by increasing the methanol concentration. The developed process can be integrated with various biorefinery processes from thermochemical, (bio)electrochemical, photovoltaic and microbial technologies. The findings from this study form a useful tool to steer the process of biological production of chemicals from biomass and other carbon and energy sources.

Keywords: Chain elongation, Selective pressure, Open-culture fermentation, Mixed-culture fermentation, Biobased chemicals, Methanol, Butyrate, $n$-Valerate

\footnotetext{
*Correspondence: david.strik@wur.nl

†Sanne M. de Smit and Kasper D. de Leeuw contributed equally to this work

Environmental Technology, Wageningen University \& Research, Axis-Z,

Bornse Weilanden 9, 6708 WG Wageningen, The Netherlands
} 


\section{Background}

The growing world population causes arable land to become more scarce, waste to be produced in larger quantities and carbon emissions to rise due to fossil fuel usage $[1,2]$. These developments emphasize the need for more sustainable and efficient production of chemicals. Microbial chain elongation processes can contribute to the realization of a more circular economy by providing a versatile approach to convert complex organic waste streams into fatty acids [short $(\mathrm{C} 1-\mathrm{C} 5)$ and medium (C6-C10) chain length]. Currently, the company ChainCraft is starting a commercial demonstration factory using ethanol-based chain elongation to produce a mixture of carboxylate salts for using them as the feed additive in the agro-food industry [3].

Several chain elongation microbial pathways are known including homoacetogenesis (Wood-Ljungdahl pathway), the Arnon-Buchanan cycle and reverse beta-oxidation [4]. Chain elongation processes utilize short carbon chains as electron acceptor and by elongating the fatty acids, the carbon atoms are getting increasingly reduced (with a limit to 6 electrons per carbon). The products of the chain elongation conversions are largely dependent on the supplied substrates. Various electron donors can be used for chain elongation such as ethanol, methanol, lactate, sugars or electrons provided via microbial electrosynthesis [4-7]. Currently, the usage of methanol as an electron donor is not sufficiently investigated and therefore is the focus of this study.

Methanol is an available electron donor [8], which could be further mass produced via various thermochemical and electrochemical methods. Substrates for methanol production include lignocellulosic biomass, waste streams (e.g. via syngas) or $\mathrm{CO}_{2}$ sources including air [9-11]. Hypothetically, when methanol is used as an electron donor for chain elongation, a cobalamin-dependent methyltransferase system, coupled to the Wood-Ljungdahl pathway, could allow for its oxidation towards acetyl-CoA, which can then be utilized in a reverse betaoxidation to reduce and elongate short chain fatty acids to longer carbon chains [12]. The short chain fatty acids acetate and propionate, which are substrates for the currently studied chain elongation process, can be produced via a hydrolysis or acidogenesis fermentation process. In addition, the acids can be produced from $\mathrm{CO}_{2}$ with pure or open-culture microbial electrosynthesis, from acetylCoA by biosynthesis and from amino acids [13-15].

The known products that can be formed within an open-culture methanol-based chain elongation of acidified supermarket waste are $n$-butyrate, iso-butyrate, $n$-valerate and $n$-caproate [16]. $n$-Valerate is a new-generation biofuel precursor and potential platform chemical. The esterification product of protonated $n$-valerate (valeric acid) can be used as an additive to diesel fuels $[17,18]$; butyrate and $n$-valerate are also suitable precursors for bioplastic (polyhydroxyalkanoates) production [19] and Kolbe electrolysis of pure $n$-valerate would lead to gasoline (octane) formation [20].

$n$-Valerate production from waste streams is a rarely investigated environmental biorefinery process [21]. $n$-Valerate formation during chain elongation processes occurred in the previous research during methanolbased chain elongation from acidified supermarket waste. However, due to the presence of various electron donors (e.g. methanol and endogenous produced ethanol), it could not be shown whether methanol-based propionate elongation occurred [22]. A pure culture experiment with Eubacterium limosum also successfully showed propionate elongation with methanol to $n$-valerate $[23,24]$. So far, no study focussed on utilizing an open culture to elongate propionate with methanol to $n$-valerate. Such open-culture microbiome could be advantageous for application since no sterilization is needed and a waste stream (i.e. organic waste) could be used as the feedstock during open-culture operation.

Fermentation of complex/mixed substrates using open-culture microbiomes typically results in a plethora of microbial processes that are either desired for chain elongation or are a competing process [25]. Reactor conditions such as temperature, $\mathrm{pH}$, gas composition and hydraulic retention time (HRT) become important selective pressure tools that will determine the product spectrum [7, 22, 25]. In this study, $\mathrm{pH}$ and hydraulic retention time were varied to selectively inhibit competitive methanol consumption processes. Slow-growing methylotrophic methanogens and acetogens [26] are competitive methanol-consuming microbes and should be kept low in numbers by maintaining a suitably low HRT. This effect is enforced by operating at a low $\mathrm{pH}$ that causes more maintenance stress and overall lowers the growth rate of all microbes [27]. Moreover, the presence of undissociated acids at a low $\mathrm{pH}$ hinders bacteria due to futile cycling caused by diffusion of undissociated acids through the cell membranes [28-30]. Therefore, in combination with a low $\mathrm{pH}$, high concentrations of volatile fatty acids could provide additional selection pressure, assuming that the microorganisms performing the desired chain elongation reactions are better suited to withstand this compared to undesired methanogenic and acetogenic microorganisms [31].

The aim of this study was to develop a continuous $n$-valerate production process using methanol-based chain elongation in an anaerobic open-culture reactor. Also, the co-production of $n$ - and iso-butyrate in addition to $n$-valerate from methanol-based elongation using, respectively, acetate and propionate was investigated. 
Two continuous reactors were developed that successfully performed methanol-based chain elongation where propionate was elongated to $n$-valerate and acetate was elongated to $n$-butyrate and iso-butyrate.

\section{Results}

\section{$n$-Valerate formation during batch experiments with $\mathrm{pH}$} ranging from 5 to 7.5

The open-culture batch experiments showed that indeed methanol-based chain elongation of propionate is feasible. The series of batch experiments started at an initial $\mathrm{pH}$ ranging from 5 to 7.5 (with steps of 0.5 ) and showed propionate elongation with methanol to form $n$-valerate (n-C5). Figure 1 shows the results of a batch that started at $\mathrm{pH}$ 7. Additional file 1: Figure S2 shows the results of the methanol-based propionate elongation batches with initial $\mathrm{pH}$ values ranging from 5.5 to 7.5 . Table 1 shows the main conversions that could occur during continuous methanol-based elongation of propionate and acetate.

\section{Continuous $n$-valerate formation with HRT $95 \mathrm{~h}$ and $\mathrm{pH}$ $5.5-5.8$}

$n$-Valerate was produced continuously during methanolbased propionate elongation by an anaerobic open-culture in a continuous reactor (Fig. 2). No methanol was consumed until the HRT was changed from 42 to $95 \mathrm{~h}$ (day 27, start of phase II). At the start of phase III $\left(\mathrm{CO}_{2}\right.$ supply, day 43), the methanol concentration decreased rapidly and increased again after the $\mathrm{pH}$ was lowered to 5.5 (Additional file 1: Figure S3, day 90). The propionate consumption increased from the moment the $\mathrm{pH}$ was decreased to 5.8 (day 43). The $n$-valerate production was low $( \pm 2.4 \mathrm{mmol} / \mathrm{L} /$ day) during phase II with $\mathrm{pH} 6.3$ (day 27-43) and increased after the $\mathrm{pH}$ was decreased to 5.8 (day 43) to a value of $9.3 \mathrm{mmol} / \mathrm{L} /$ day. A slight increase in the $n$-valerate productivity (to $9.7 \mathrm{mmol} / \mathrm{L} /$ day) and concentration $(40 \mathrm{mM})$ followed in phase IV, when the pH was 5.5 (day 111-120) (Fig. 3, Table 2). The concentration profiles of the most important compounds with
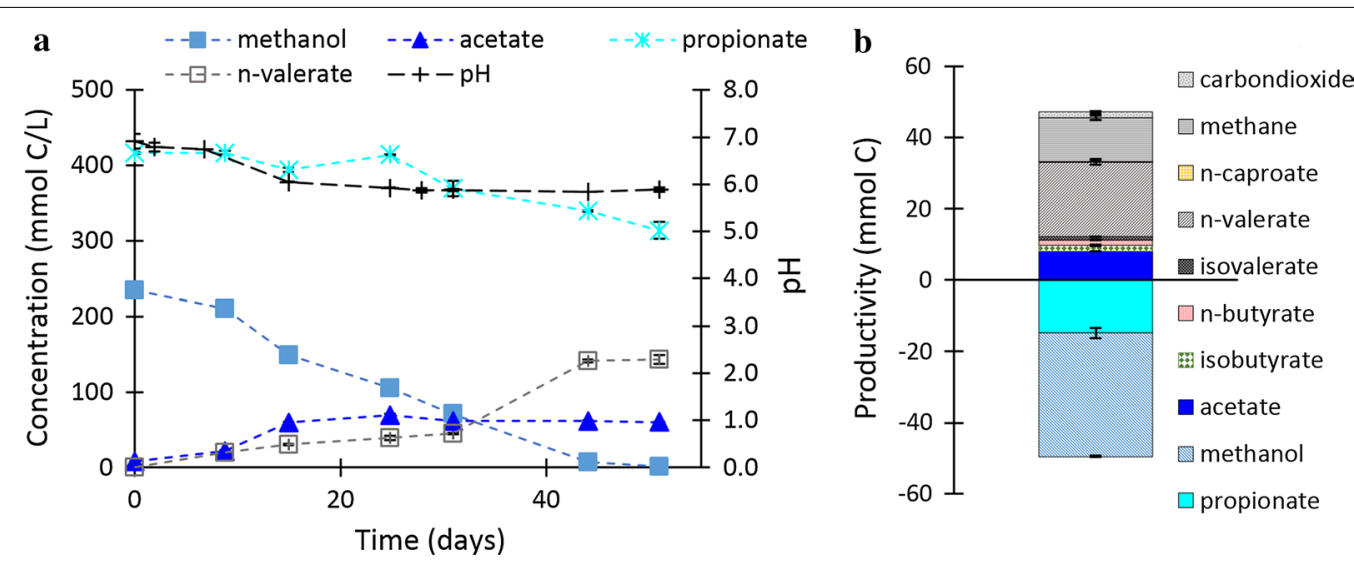

Fig. 1 Concentration profile (a) during a batch experiment with methanol and propionate with the initial pH 7 at $308 \mathrm{~K}$. Initially (day $0-25$ ), acetate is formed via $\mathrm{CO}_{2}$ elongation with methanol concurrently with a $\mathrm{pH}$ drop. Propionate elongation to valerate starts slowly in the beginning; however, after 40 days when the $\mathrm{pH}$ is 5.8 it is the most prevalent metabolic activity. The total conversions at the end of the batch experiment are shown as well (b). The error bars represent the minimum and maximum values measured in the duplo experiments

Table 1 Overview of main catabolic conversions shown occurring during continuous methanol-based propionate and acetate elongation under anaerobic conditions at $308 \mathrm{~K}$ and pH 5.8 with the Gibbs free energy of the reactions

\begin{tabular}{llll}
\hline $\mathbf{N r}$ & Description & Catabolic reaction & $\Delta \mathbf{G}_{\mathbf{r}}^{\mathbf{1}}$ (kJ/reaction) \\
\hline 1 & Methylotrophic methanogenesis [32] & $4 \mathrm{CH}_{3} \mathrm{OH} \rightarrow 3 \mathrm{CH}_{4}+\mathrm{HCO}_{3}^{-}+\mathrm{H}_{2} \mathrm{O}+\mathrm{H}^{+}$ & -310.8 \\
2 & Methylotrophic acetogenesis [33] & $4 \mathrm{CH}_{3} \mathrm{OH}+2 \mathrm{HCO}_{3}^{-} \rightarrow 3 \mathrm{CH}_{3} \mathrm{COO}^{-}+\mathrm{H}^{+}+4 \mathrm{H}_{2} \mathrm{O}$ & -178.7 \\
3 & $n$-Valerate formation from methanol and propionate & $2 \mathrm{CH}_{3} \mathrm{OH}+\mathrm{C}_{3} \mathrm{H}_{5} \mathrm{O}_{2}^{-} \rightarrow \mathrm{C}_{5} \mathrm{H}_{9} \mathrm{O}_{2}^{-}+2 \mathrm{H}_{2} \mathrm{O}$ & -106.1 \\
4 & $n$-Butyrate formation from methanol and acetate [24] & $2 \mathrm{CH}_{3} \mathrm{OH}+\mathrm{CH}_{3} \mathrm{COO}^{-} \rightarrow \mathrm{CH}_{3}\left(\mathrm{CH}_{2}\right)_{2} \mathrm{COO}^{-}+2 \mathrm{H}_{2} \mathrm{O}$ & -106.1 \\
5 & Iso-butyrate formation from methanol and acetate & $2 \mathrm{CH}_{3} \mathrm{OH}+\mathrm{CH}_{3} \mathrm{COO}^{-} \rightarrow\left(\mathrm{CH}_{3}\right)_{2} \mathrm{CHCOO}^{-}+2 \mathrm{H}_{2} \mathrm{O}$ & -106.1 \\
6 & Acetotrophic methanogenesis [34] & $\mathrm{CH}_{3} \mathrm{COO}^{-}+\mathrm{H}_{2} \mathrm{O} \rightarrow \mathrm{CH}_{4}+\mathrm{HCO}_{3}^{-}$ & -49.9 \\
7 & Hydrogenogenic propionate degradation [35, 36] & $\mathrm{CH}_{3} \mathrm{CH}_{2} \mathrm{COO}^{-}+3 \mathrm{H}_{2} \mathrm{O} \rightarrow \mathrm{CH}_{3} \mathrm{COO}^{-}+\mathrm{HCO}_{3}^{-}+\mathrm{H}^{+}+3 \mathrm{H}_{2}$ & 26.7 with pH $\mathrm{pH}_{2} 100 \mathrm{~Pa}^{-}$ \\
8 & Hydrogenotrophic methanogenesis [37] & $4 \mathrm{H}_{2}+\mathrm{HCO}_{3}^{-}+\mathrm{H}^{+} \rightarrow \mathrm{CH}_{4}+3 \mathrm{H}_{2} \mathrm{O}$ & -68.4 with pH \\
9 & Hydrogenotrophic acetogenesis [38] & $4 \mathrm{H}_{2}+2 \mathrm{HCO}_{3}^{-}+\mathrm{H}^{+} \rightarrow \mathrm{CH}_{3} \mathrm{COO}^{-}+4 \mathrm{H}_{2} \mathrm{O}$ & -36.1 with pH \\
\hline
\end{tabular}

The calculation of the Gibbs free energy is shown in Additional file $1[67,68]$ 


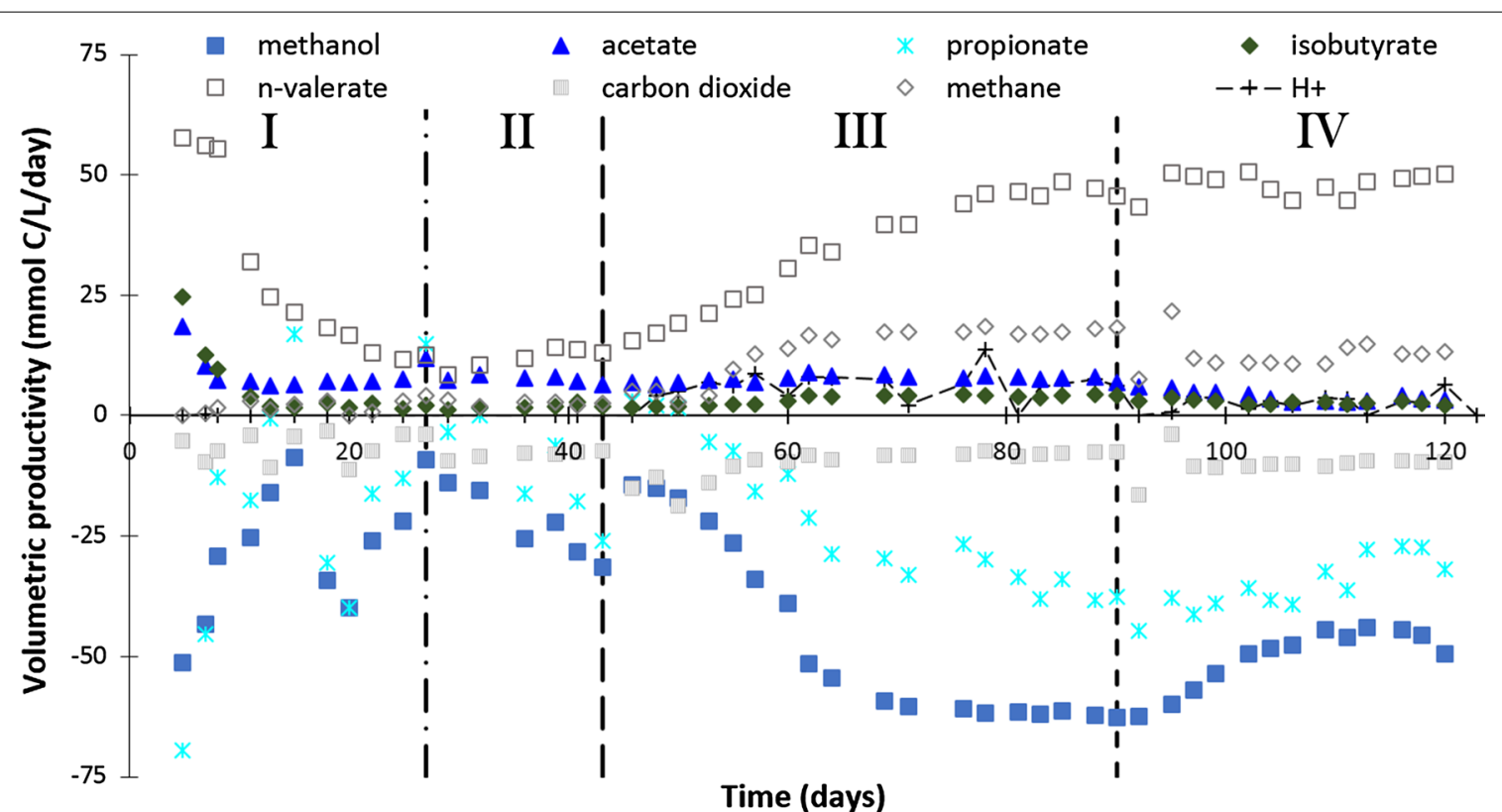

Fig. 2 Volumetric productivities in time during continuous methanol-based propionate elongation in an anaerobic open-culture reactor at $309 \mathrm{~K}$. The production of protons in $\mathrm{mmol} / \mathrm{day}$ is also shown (- +- - ). The vertical lines indicate the major changes in the setup: change of the hydraulic retention time (HRT) from 42 to $95 \mathrm{~h}(\boldsymbol{-} \mathbf{-})$ ), pH change from 6.3 to 5.8 ( $-\boldsymbol{C}$ ) and pH change from 5.8 to 5.5 ( - - - )

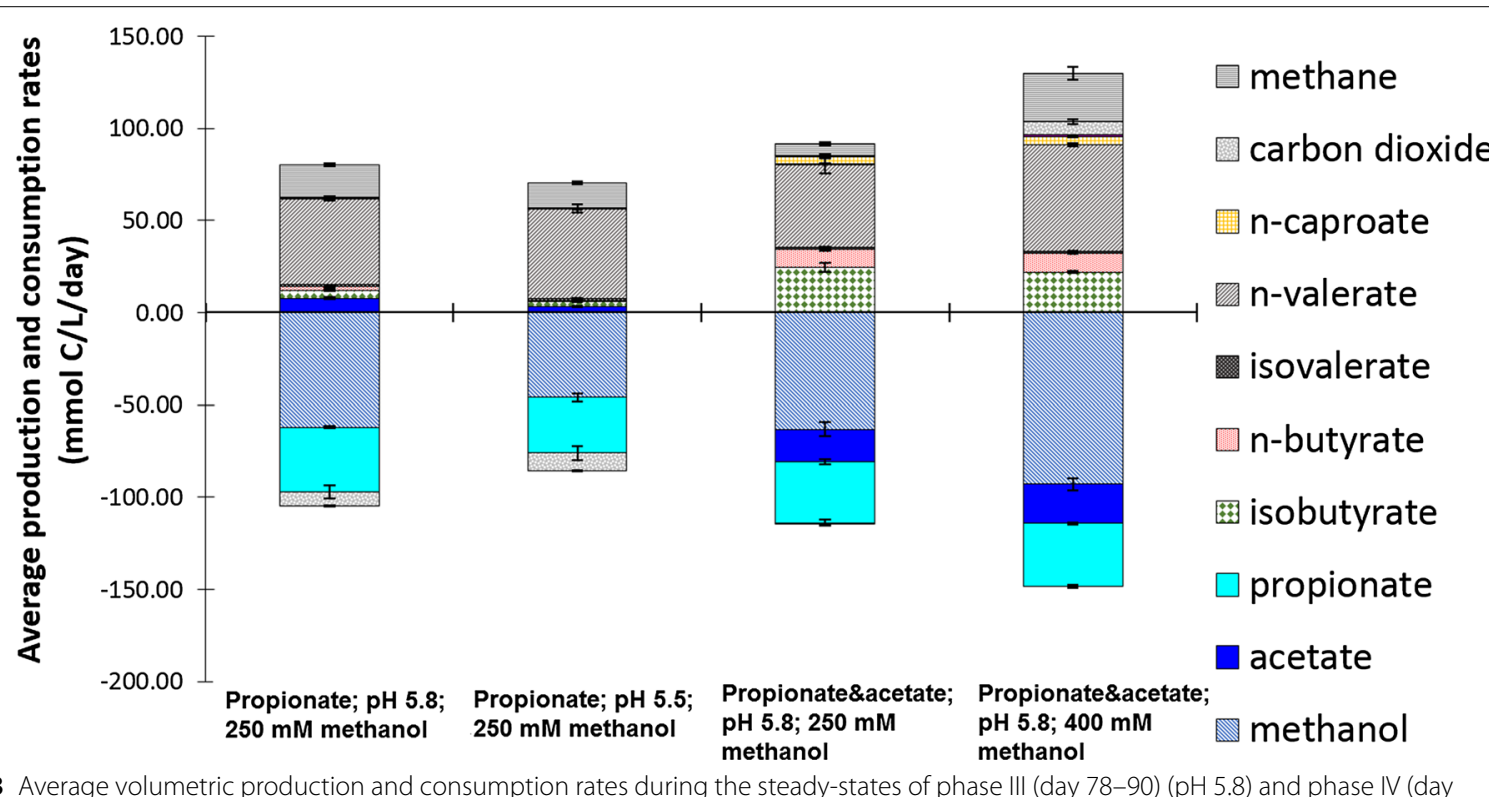

Fig. 3 Average volumetric production and consumption rates during the steady-states of phase III (day 78-90) (pH 5.8) and phase IV (day 111-120) (pH 5.5) of continuous methanol-based propionate elongation in an anaerobic open-culture reactor and during the steady-state of phase V (day 64-71) (methanol in influent $250 \mathrm{mM}$ ) and during the last days of phase VI (day 97-104) (methanol in influent $400 \mathrm{mM}$ ) of continuous methanol-based propionate and acetate elongation in an anaerobic open-culture reactor at $309 \mathrm{~K}$. The error bars represent the minimum and maximum values measured during the phase. Table 2 shows an overview of the average concentrations, productivities and relative product selectivities of $n$-valerate during the same four phases. The carbon balances for the four steady-states were $88 \pm 2,93 \pm 4,88 \pm 4$ and $92 \pm 3 \%$ from left to right, the electron balances were $92 \pm 2,98 \pm 4,87 \pm 4$ and $91 \pm 3 \%$, respectively. The balances can be found in Additional file 1: Figure S3 
Table 2 Average concentrations, volumetric productivities and relative product selectivities of $n$-valerate during the steady-states of phase III (day 78-90) (pH 5.8) and phase IV (day 111-120) (pH 5.5) of continuous methanolbased propionate elongation and during the steady-state of phase $V$ (day 64-71) (methanol in influent $250 \mathrm{mM}$ ) and during the last days of phase VI (day 97-104) (methanol in influent $400 \mathrm{mM}$ ) of continuous methanol-based propionate and acetate elongation in an anaerobic open-culture reactor at $309 \mathrm{~K}$

\begin{tabular}{|c|c|c|c|c|}
\hline & $\begin{array}{l}\text { Propionate; pH 5.8; } \\
250 \text { mM methanol }\end{array}$ & $\begin{array}{l}\text { Propionate; pH 5.5; } \\
250 \text { mM methanol }\end{array}$ & $\begin{array}{l}\text { Propionate and acetate; } \\
\mathrm{pH} 5.8 ; 250 \mathrm{mM} \\
\text { methanol }\end{array}$ & $\begin{array}{l}\text { Propionate and acetate; } \\
\text { pH 5.8; } 400 \mathrm{mM} \\
\text { methanol }\end{array}$ \\
\hline Average $n$-valerate concentration (mM) & $37.1 \pm 0.9$ & $38.4 \pm 1.4$ & $33.9 \pm 2.3$ & $42.8 \pm 0.7$ \\
\hline Average $n$-valerate productivity (mmol/L/day) & $9.3 \pm 0.2$ & $9.7 \pm 0.4$ & $9.0 \pm 1.0$ & $11.5 \pm 0.2$ \\
\hline Average $n$-valerate selectivity (wt\%) & 58 & 70 & 49 & 43 \\
\hline
\end{tabular}

the carbon and electron balances are shown in Additional file 1: Figure S3A.

Formation of $n$ - and iso-butyrate in addition to $n$-valerate during simultaneous elongation of acetate and propionate The continuous experiment with simultaneous propionate and acetate elongation with methanol showed formation of both $n$ - and iso-butyrate and $n$-valerate. The concentration profile of the most important compounds is shown in Additional file 1: Figure S3B. A steady-state was reached after 64 days; subsequently, the methanol concentration in the influent was increased (from 250 to $400 \mathrm{mM}$ ) to study whether a higher methanol concentration would lead to a higher chain elongation productivity. The concentrations of methanol in the reactor were $27 \pm 4 \mathrm{mM}$ and $76 \pm 14 \mathrm{mM}$, respectively, during the steady-states with $250 \mathrm{mM}$ methanol and $400 \mathrm{mM}$ methanol in the reactor influent. After the increase of the methanol concentration in the influent from 250 to $400 \mathrm{mM}$, the $n$-valerate formation increased, whilst the productivities of iso-butyrate and $n$-butyrate stayed constant compared to the phase with $250 \mathrm{mM}$ methanol in the influent (Fig. 3 and Additional file 1: Figure S4). More iso-butyrate was formed compared to $n$-butyrate; the isobutyrate $/ n$-butyrate ratios were $2.5 \pm 0.3$ and $2.1 \pm 0.1$, respectively, in the steady-states with 250 and $400 \mathrm{mM}$ methanol in the influent of the reactor with continuous methanol-based propionate and acetate elongation (Fig. 3: right two bars). Small amounts $(1 \mathrm{mM})$ of isovalerate were observed during both continuous methanol-based chain elongation processes. This iso-valerate is likely produced from the amino acids in the yeast extract present in the medium $[39,40]$.

\section{Increase of relative methane selectivity after increase} of methanol concentration

The increase of the methanol concentration in the reactor increased the $n$-valerate productivity, but decreased the relative selectivity for $n$-valerate production from 49 to $43 \mathrm{wt} \%$ of the total carbon containing products (Fig. 4 , Table 2). The main reason for the decreased selectivity is the net carbon dioxide formation and the increased methane production that occurred with a higher methanol concentration in the influent.

\section{Clostridium luticellarii (species) mainly present during both acetate and propionate elongation}

Within the methanol chain elongation reactor, two orders predominantly were present: Clostridiales and Thermoplasmatales. Table 3 shows the composition of the microbial communities at the end of the two last phases in both the continuous methanol-based propionate elongation reactor and the continuous methanol-based acetate and propionate elongation reactor. The most abundant OTU from the Clostridiales bacteria $(\sim 20 \%, \sim 17 \%, \sim 43 \%$ and $\sim 17 \%$ of the total OTU count, respectively, for the phases from left to right in Table 3) appeared to be highly similar to Clostridium luticellarii (99.72\% similarity, Additional file 1: Table S12). In Additional file 1: Tables S10-S13, more extensive information on genus level relative abundances, OTU counts and NCBI Megablast results can be found.

\section{Discussion}

$n$-Valerate formation during batch experiments with $\mathrm{pH}$ ranging from 5 to 7.5

During the batches, three predominant metabolic groups were deducted from the consumed substrates and produced biochemicals: (1) methylotrophic methanogens, (2) methylotrophic acetogens and (3) methanol-based propionate elongation (Table 1 ). Also traces of $n$-butyrate and iso-butyrate were found (Fig. 1b) which indicates methanol-based acetate elongation activity.

The degree in which the main metabolic activities occurred depended heavily on the initial $\mathrm{pH}$ and final concentrations. An initial $\mathrm{pH}$ of 7 and 7.5 caused some methanogenic activity and acetogenesis to occur in the beginning of the batch, whereas methanol-based chain 

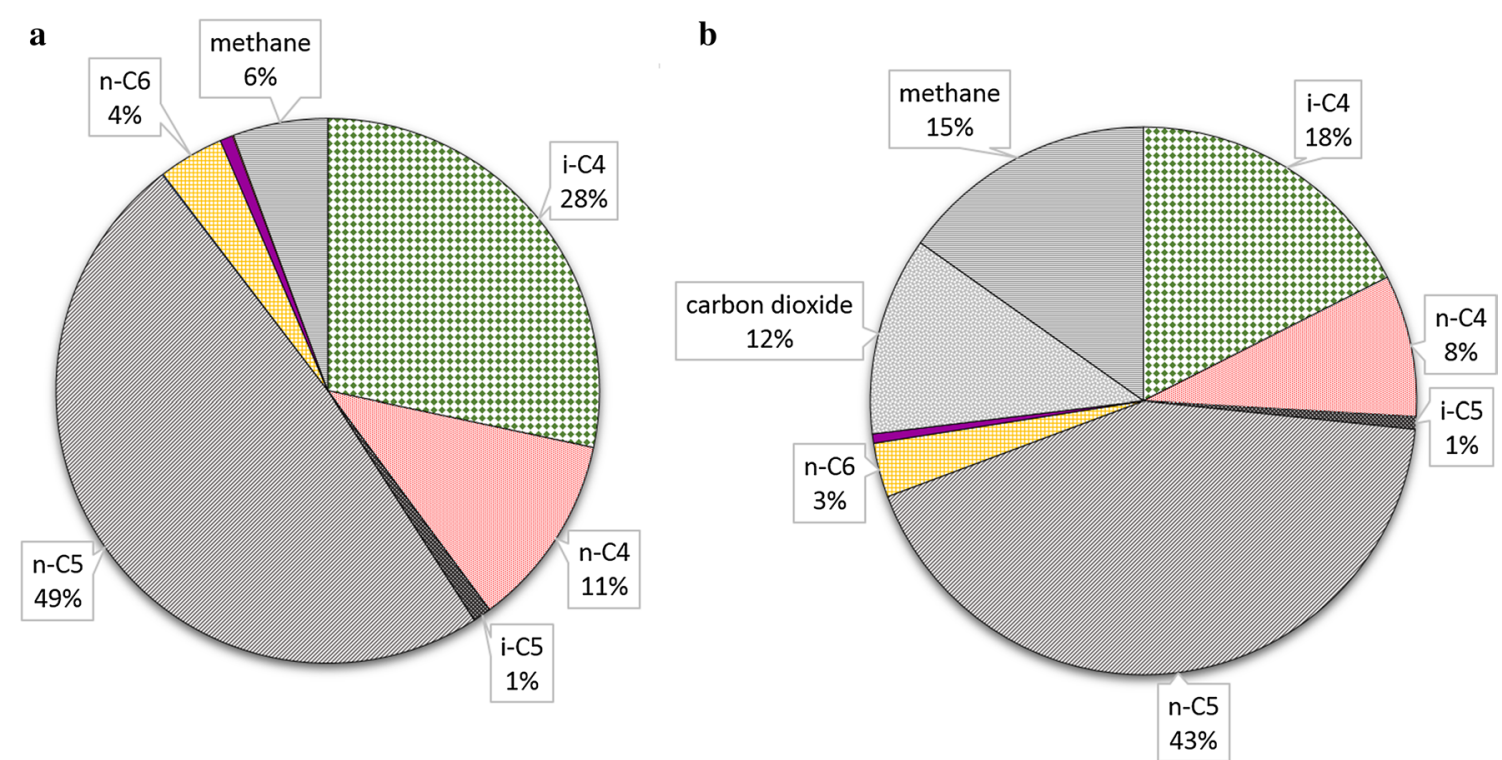

Fig. 4 Relative selectivity of the formed $n$-butyrate ( $n$-C4), iso-butyrate (i-C4), $n$-valerate (n-C5), iso-valerate (i-C5), $n$-caproate ( $n$-C6), carbon dioxide $\left(\mathrm{CO}_{2}\right)$ and methane $\left(\mathrm{CH}_{4}\right)$ of continuous methanol-based propionate and acetate elongation in an anaerobic open-culture reactor at $36^{\circ} \mathrm{C}$ at the steady-state with $250 \mathrm{mM}$ methanol in the influent (a) (day 64-71) and at the last days with $400 \mathrm{mM}$ methanol in the influent (b) (day 111-120). The values are calculated based on the production rates in $\mathrm{g} / \mathrm{L} /$ day; the total production rates were $1.37 \pm 0.26$ (a) and $2.12 \pm 0.18$ (b) $\mathrm{g} / \mathrm{L} / \mathrm{day}$

elongation of propionate to $n$-valerate caught on after approximately 30 days when $\mathrm{pH}$ had already dropped to $5.8 \pm 0.1$. In the batch that started at $\mathrm{pH} 6.5$, this pattern was similar but showed a longer lag phase and more extended/slowed production profile. The batches done at $\mathrm{pH} 6$ and lower showed no significant production after 60 days (Additional file 1: Figure S2).

\section{Continuous $n$-valerate formation with HRT $95 \mathrm{~h}$ and $\mathrm{pH}$ $5.5-5.8$}

The hydraulic retention time (HRT) and the $\mathrm{pH}$ appeared to be critical for continuous $n$-valerate production. The HRT of $42 \mathrm{~h}$ appeared to be too short for the valerate producing organisms, since the concentration of $n$-valerate and the $n$-valerate productivity decreased exponentially after the startup of the experiment (Fig. 2: day 0-27). The $n$-valerate-producing culture probably washed out during the first phase, since a decrease in optical density was by eye observed. For this study, an HRT of $95 \mathrm{~h}$ was used, so most microorganisms that carry out competitive methanol-consuming processes (Table 1R1 and R2) could now theoretically grow in the continuous reactor, based on their growth rates found in the literature [26]. The minimum HRT will be between 42 and $95 \mathrm{~h}$.

The chain elongation reactions occurred at $\mathrm{pH}$ values between 5.5 and 5.8 during both batch and continuous experiments. A pH of 5.5 is optimal for $n$-valerate formation during continuous methanol-based propionate elongation (Fig. 2). The $\mathrm{pH}$ decrease from 5.8 to 5.5 led to selectivity increase for $n$-valerate formation from methanol and propionate (from 58 to $70 \%$, Table 2), which was attributed to two causes.

First, the acetate formation (Table 1R2) decreased after the $\mathrm{pH}$ was lowered from 5.8 to 5.5 (day 90) (Fig. 2). The theoretical available amount of dissolved carbon dioxide was maintained equal at $\mathrm{pH} 5.8$ and 5.5 , so substrate availability was not the reason for the decreased acetogenic activity (Additional file 1: Figure S1). The acetogenic activity could decrease at lower $\mathrm{pH}$ [41] or at higher concentration of undissociated acids present at the lower $\mathrm{pH}$ [28]. Less acetate was apparently available for $n$ - and iso-butyrate formation at pH 5.5 (Table 1R5), so the $n$ - and iso-butyrate formation decreased as well.

Second, the methanogenic productivity decreased after the $\mathrm{pH}$ was lowered from 5.8 to 5.5 (day 90) (Fig. 3). This finding is supported by the decreased relative abundance of the Thermoplasmatales family at $\mathrm{pH} 5.5$ compared to $\mathrm{pH} 5.8$ in the continuous methanol-based propionate elongation reactor (Table 3 ). The Thermoplasmatales family contains methane-producing archaea; they were identified to fall within uncultured species of the methylotrophic methanogen genus Candidatus Methanogranum [42] (Table 1R1). These archaea are known to utilize methanol as a substrate for methane formation, which well fits the observed methanogenesis in our system (Fig. 3) [43]. The methanogenesis inhibition with the $\mathrm{pH}$ decrease could, e.g., be caused by either the higher 
Table 3 Overview of the relative abundances within the microbiomes, given in percentage at order level

\begin{tabular}{|c|c|c|c|c|c|c|c|c|}
\hline \multirow[t]{2}{*}{ Order } & \multicolumn{2}{|c|}{$\begin{array}{l}\text { Propionate; pH 5.8; } \\
250 \text { mM methanol }\end{array}$} & \multicolumn{2}{|c|}{$\begin{array}{l}\text { Propionate; pH 5.5; } \\
250 \text { mM methanol }\end{array}$} & \multicolumn{2}{|c|}{$\begin{array}{c}\text { Propionate\&acetate; } \\
\text { pH 5.8; } 250 \mathrm{mM} \\
\text { methanol }\end{array}$} & \multicolumn{2}{|c|}{$\begin{array}{c}\text { Propionate\&acetate; } \\
\text { pH 5.8; } 400 \mathrm{mM} \\
\text { methanol }\end{array}$} \\
\hline & 1 & 2 & 1 & 2 & 1 & 2 & 1 & 2 \\
\hline Clostridiales & $42.30 \%$ & $43.20 \%$ & $39.10 \%$ & $46.70 \%$ & $58.10 \%$ & $58.40 \%$ & $38.00 \%$ & $34.60 \%$ \\
\hline $\begin{array}{l}\text { Thermoplasmatales } \\
\text { (Archaea) }\end{array}$ & $29.30 \%$ & $32.70 \%$ & $25.00 \%$ & $21.60 \%$ & $18.10 \%$ & $19.20 \%$ & $33.90 \%$ & $38.20 \%$ \\
\hline Pseudomonadales & $6.30 \%$ & $3.20 \%$ & $0.00 \%$ & $0.00 \%$ & $0.10 \%$ & $0.10 \%$ & $0.00 \%$ & $0.10 \%$ \\
\hline Rhodocyclales & $4.90 \%$ & $3.30 \%$ & $0.00 \%$ & $0.00 \%$ & $0.00 \%$ & $0.00 \%$ & $0.00 \%$ & $0.00 \%$ \\
\hline Bacteroidales & $3.40 \%$ & $4.00 \%$ & $12.10 \%$ & $11.50 \%$ & $8.50 \%$ & $9.00 \%$ & $10.30 \%$ & $10.30 \%$ \\
\hline $\begin{array}{l}\text { Methanomicrobiales } \\
\text { (Archaea) }\end{array}$ & $2.20 \%$ & $2.80 \%$ & $5.10 \%$ & $3.30 \%$ & $0.20 \%$ & $0.30 \%$ & $4.50 \%$ & $4.00 \%$ \\
\hline Coriobacteriales & $2.00 \%$ & $2.20 \%$ & $4.30 \%$ & $3.90 \%$ & $0.40 \%$ & $0.40 \%$ & $1.10 \%$ & $1.00 \%$ \\
\hline Burkholderiales & $1.30 \%$ & $0.70 \%$ & $2.10 \%$ & $1.90 \%$ & $1.00 \%$ & $0.90 \%$ & $1.20 \%$ & $1.30 \%$ \\
\hline Campylobacterales & $1.30 \%$ & $1.40 \%$ & $0.00 \%$ & $0.00 \%$ & $0.10 \%$ & $0.10 \%$ & $0.00 \%$ & $0.10 \%$ \\
\hline Synergistales & $0.80 \%$ & $1.00 \%$ & $0.40 \%$ & $0.40 \%$ & $0.30 \%$ & $0.20 \%$ & $0.30 \%$ & $0.30 \%$ \\
\hline Spirochaetales & $0.50 \%$ & $0.50 \%$ & $0.50 \%$ & $0.40 \%$ & $0.40 \%$ & $0.50 \%$ & $0.50 \%$ & $0.40 \%$ \\
\hline Erysipelotrichales & $0.50 \%$ & $0.50 \%$ & $7.60 \%$ & $6.60 \%$ & $9.40 \%$ & $8.20 \%$ & $8.30 \%$ & $8.00 \%$ \\
\hline Selenomonadales & $0.30 \%$ & $0.30 \%$ & $1.70 \%$ & $1.70 \%$ & $0.60 \%$ & $0.40 \%$ & $0.30 \%$ & $0.30 \%$ \\
\hline $\begin{array}{l}\text { Methanobacteriales } \\
\text { (Archaea) }\end{array}$ & $0.10 \%$ & $0.10 \%$ & $0.10 \%$ & $0.10 \%$ & $0.00 \%$ & $0.00 \%$ & $0.00 \%$ & $0.00 \%$ \\
\hline Sum of all order & $95.20 \%$ & $95.70 \%$ & $97.90 \%$ & $98.10 \%$ & $97.40 \%$ & $97.70 \%$ & $98.50 \%$ & $98.50 \%$ \\
\hline Other orders & $4.80 \%$ & $4.30 \%$ & $2.10 \%$ & $1.90 \%$ & $2.60 \%$ & $2.30 \%$ & $1.50 \%$ & $1.50 \%$ \\
\hline Total OTU count & 132846 & 221728 & 197444 & 208429 & 189896 & 194669 & 183205 & 200691 \\
\hline
\end{tabular}

The samples were taken at the end of the steady-states of phase III (day 90) (pH 5.8) and phase IV (day 125) (pH 5.5) of continuous methanol-based propionate elongation in an anaerobic open-culture reactor and at the end of the steady-state of phase $\mathrm{V}$ (day 69 ) (methanol in influent $250 \mathrm{mM}$ ) and during the last day of phase $\mathrm{VI}$ (day 106) (methanol in influent $400 \mathrm{mM}$ ) of continuous methanol-based propionate and acetate elongation in an anaerobic open-culture reactor at $309 \mathrm{~K}$. For all biomass samples, the duplo results are shown indicated by 1 and 2 . More detailed information and the relative abundances found for the inoculum samples can be found in Additional file 1: Tables S10 to S13

extracellular proton concentration or the higher concentration of undissociated volatile fatty acids [28-30].

\section{Increase of methanol concentration caused increase of both $n$-valerate productivity and methanogenesis} The $n$-valerate production improved after the increase of the methanol concentration in the influent, whilst the prior methanol concentration did not limit the $n$ and iso-butyrate production (Fig. 3). Methylotrophic methanogenesis (Table 1R1), one of the competing methanol-consuming processes, increased as a result of the high-methanol influent concentration in phase VI. The relative abundance of the Candidatus Methanogranum genus also increased with the increasing methanol concentration (Table 3), indicating a growth of the methanogenic bacteria community. The methanol concentration in the influent and reactor was the only parameter that changed between the two steady-states shown in Fig. 4, indicating that the methylotrophic methanogenesis was limited by the methanol concentration $(27 \pm 4 \mathrm{mM})$ during the first steady-state. Further, examination of the $K_{\mathrm{S}}$ value for methylotrophic methanogenesis under the described conditions can verify whether kinetics were indeed limiting at lower methanol concentrations. The yield of $n$-valerate over propionate was $1.01 \mathrm{~mol} / \mathrm{mol}$, whilst the yield of $n$ - and iso-butyrate over acetate was $0.76 \mathrm{~mol} / \mathrm{mol}$ during phase VI. The lower yield of butyrate over acetate indicates that acetate was consumed for other processes than butyrate formation; likely, acetate was utilized for biomass formation. 
Clostridium luticellarii (species) dominant candidate for continuous methanol-based propionate elongation Clostridium luticellarii is a known butyrate-producing strain (Additional file 1: Table S11) within the Clostridium sensu stricto 12 genus. It shares the highest similarities with Clostridium ljungdahlii and Clostridium kluyveri [44]. C. luticellarii is the prime candidate for performing the methanol-based chain elongation, which well fits its similarities to a Wood-Ljungdahl-harbouring (C. ljungdahlii) microorganism and a reverse $\beta$-oxidation-harbouring (C. kluyverii) microorganism. The OTU with a high similarity (100\% cover, $99.72 \%$ identity, Additional file 1: Table S12) to Clostridium luticellarii has the highest relative abundance among the Clostridium sensu stricto 12 for both the methanol-based propionate elongation reactor and the methanol-based propionate and acetate elongation reactor. This finding suggests that $C$. luticellarii is responsible for both the elongation reactions from acetate to $n$ - and iso-butyrate (Table 1R4 and R5) and the elongation from propionate to $n$-valerate (Table 1R3). The proposed mechanism by which $C$. luticellarii performs the methanol-based chain elongation reaction (for propionate elongation to $n$-valerate) is shown in Fig. 5. Methanol as electron donor is known to be metabolized within the Wood-Ljungdahl pathway where some methanol is reduced to $\mathrm{CO}$, whilst the rest of the methanol is used for elongation with this CO to form acetyl-CoA $[45,46]$. It was observed in this study that the electron acceptor (acetate and propionate) was always elongated with two-carbon units. This stoichiometry suggests that the elongation is executed via an acetyl-CoA thiolase-driven reaction similar to reverse beta-oxidation [47, 48]. The proposed route should be verified by isolating the responsible strain and by performing a genome analysis to identify the corresponding enzymes.

\section{Shift in catabolic conversions as a result of the $\mathrm{pH}$ change and the methanol increase}

During continuous methanol-based propionate elongation, the $\mathrm{pH}$ decrease from 5.8 to 5.5 caused a decrease in both acetate formation and $n$-valerate degradation (Fig. 6a, b). The microbial analysis that was performed during the steady-state at $\mathrm{pH} 5.8$ was combined with the stoichiometric analysis to obtain an overview of the main catabolic conversions (Fig. 6a). The proton production decreased after the $\mathrm{pH}$ decrease (Additional file 1: Figure S3), suggesting methylotrophic acetogenesis (Table 1R2) is less likely to occur at pH 5.5.

The change in the molar yield of $n$-valerate over propionate (from 0.80 at $\mathrm{pH} 5.8$ to 0.97 at $\mathrm{pH} 5.5$ ) indicated that the degradation reaction of propionate (Table 1R7) did not occur during the steady-state at pH 5.5 (Fig. 6b). Only very small traces of $\mathrm{H}_{2}$ were observed during the continuous methanol-based elongation of acetate ( $\max$ $0.02 \mathrm{mmol} / \mathrm{L} /$ day) and during the simultaneous elongation of acetate and propionate ( $\max 0.03 \mathrm{mmol} / \mathrm{L} /$ day) Some blasted OTUs from the Clostridium sensu stricto 21 genus found during this study (Additional file 1: Table S11) were also found in mixed cultures where hydrogen production was observed $[52,53]$, so possibly propionate degradation by $\mathrm{H}_{2}$-producing bacteria took place at $\mathrm{pH}$ 5.8. However, the Gibbs free energy of the propionate degradation is positive at $100 \mathrm{~Pa} \mathrm{H}_{2}$ (becomes $<-20 \mathrm{~kJ} /$ reaction at $0.1 \mathrm{~Pa}$ ) making this reaction unlikely to have occurred. The conversion is dashed since it is unknown whether hydrogen produced during the propionate degradation. The competing methanol and propionate consumption processes (2 and 7) were almost completely inhibited at pH 5.5 (Fig. 6).

The increase of the methylotrophic methanogenesis conversion (Table 1R1) is the main change observed from the stoichiometric analysis of the steady-states in the reactor with simultaneous acetate and propionate elongation (Fig. 6c, d). The molar ratio between the productivity of methane and $\mathrm{CO}_{2}$ is 3:1 (Fig. 3), supporting the proposed methylotrophic methanogenesis (Table 1R1). The molar yield of $n$-valerate per propionate increased (from 0.81 to 1.01) after the increased methanol concentration in the influent. This indicates that the propionate degradation reaction (Table 1R7) mainly occurred during the phase with $250 \mathrm{mM}$ methanol in the influent. Since no significant net hydrogen production was measured in the reactor during the continuous acetate and propionate elongation process, a hydrogen-consuming process must have taken place if propionate was degraded to bicarbonate and hydrogen. Hydrogenotrophic methanogenesis (Table 1R8) and hydrogenotrophic acetogenesis (Table 1R9) are suggested to have occurred as hydrogenconsuming process during the steady-state with $250 \mathrm{mM}$ methanol in the influent (Fig. 6c).

The molar yield of $n$ - and iso-butyrate over acetate was 0.99 during the steady-state with $250 \mathrm{mM}$ methanol in the influent, so when propionate degradation occurred, the hereby produced acetate (Table 1R7) has been consumed in another process. Acetotrophic methanogenesis (Table 1R6) is suggested to have occurred during the steady-state with $250 \mathrm{mM}$ methanol in the influent (Fig. 6c). The molar yield of $n$ - and iso-butyrate over acetate decreased (to 0.76 ) after the methanol concentration in the influent was increased, so presumably acetate was consumed in other processes than butyrate formation during the phase with $400 \mathrm{mM}$ methanol in the influent (Fig. 6d). 


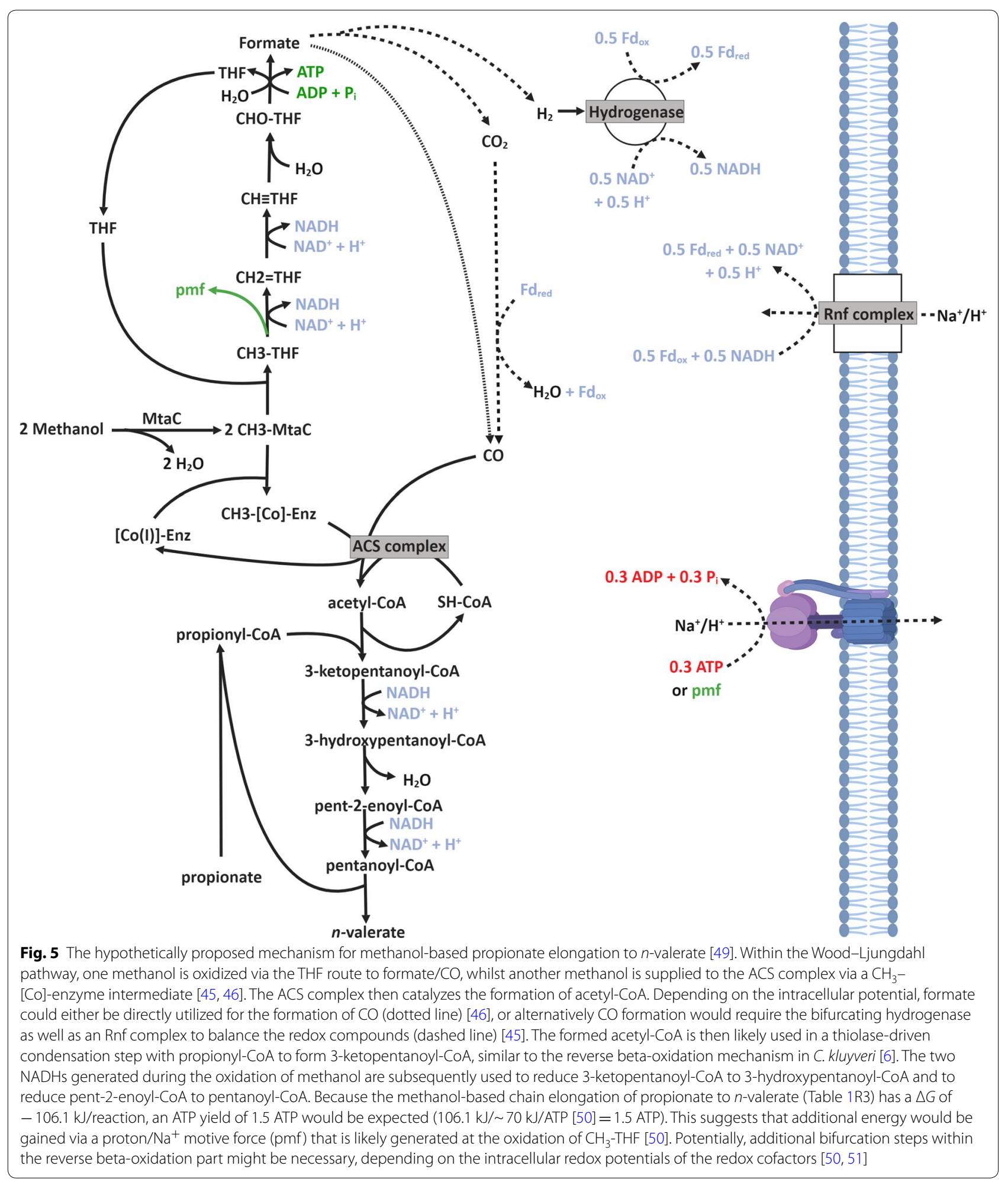


a Methanol based propionate elongation: $\mathrm{pH} 5.8$

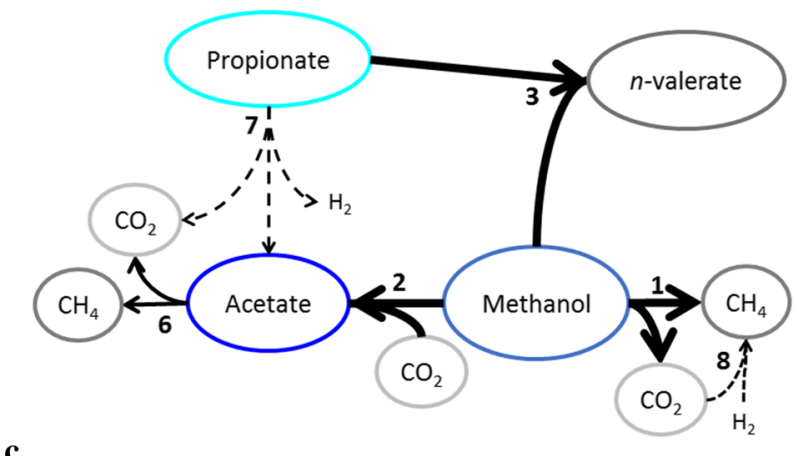

c

Methanol based elongation of acetate and propionate: $250 \mathrm{mM}$ methanol in the influent

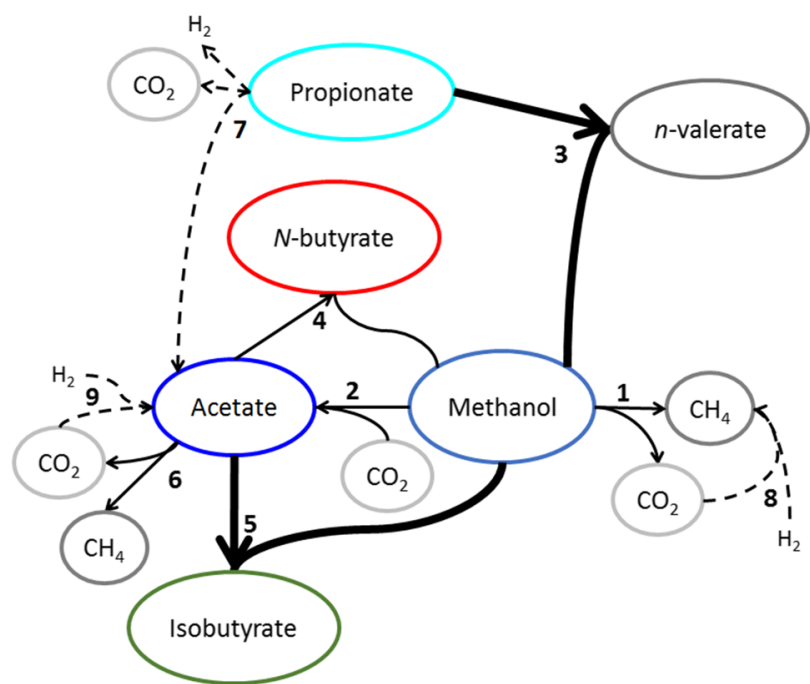

b

Methanol based propionate elongation: $\mathrm{pH} 5.5$

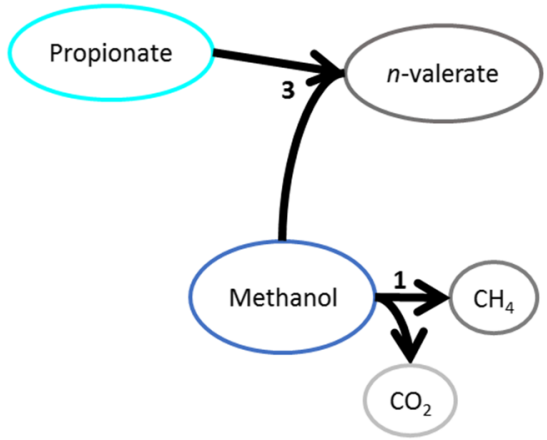

d

Methanol based elongation of acetate and propionate: $400 \mathrm{mM}$ methanol in the influent

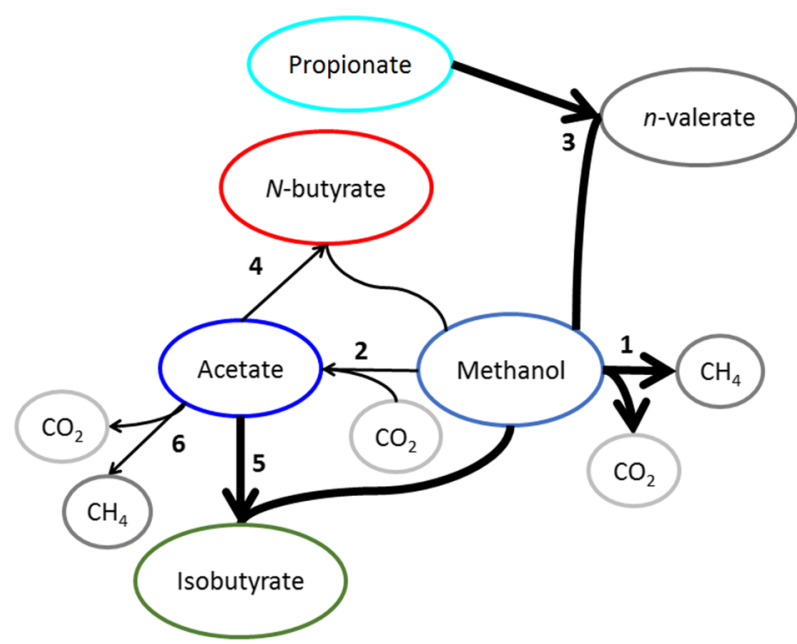

Fig. 6 Schematic overview of the proposed main conversions that occurred during continuous methanol-based elongation of propionate (Pro) and simultaneous propionate and acetate (Pro\&Ac) elongation at $309 \mathrm{~K}$. The four scenarios represent the steady-states in the propionate elongation reactor at pH 5.8 (a) and pH 5.5 (b) and in the simultaneous propionate and acetate elongation reactor with 250 (c) and 400 (d) mM methanol in the reactor influent. The conversions with dashed arrows are proposed to maintain the electron balance. The main reactions are indicated with thicker arrows. For simplicity, only the productivities of the compounds with a value higher than $5 \mathrm{mmol} / \mathrm{L} /$ day are shown. The reaction equations and Gibbs free energy of the numbered conversions can be found in Additional file 1

\section{Outlook on application and process improvements}

Microbially formed $n$-valerate can become an additional platform chemical for various applications. Instead of sugarcane molasses [54], more and possible cheaper substrates such as organic waste could be used as a substrate for $n$-valerate production. A recent study from Gonzalez-Garcia et al. [14] showed that propionate production can be achieved via various metabolic pathways. Microbially produced propionate will enter the market in the near future [14], which will make $n$-valerate production easier and more attractive. Mixtures of acetate and propionate can not only be produced from the earlier used supermarket/food waste [22], but are also reported for microbial electrosynthesis from $\mathrm{CO}_{2}[15,55]$. Methanol can be produced not only from syngas from lignocellulose or waste, but also by thermochemical $\mathrm{CO}_{2}$ conversions $[9,11,56]$. The electrosynthesis and thermochemical processes can be driven by electricity obtained from photovoltaics. In summary, with substrates from various waste sources and renewable energy, the developed process can be applied in the integrated and sustainable $n$-valerate biorefinery processes.

The developed $n$-valerate formation process can be further improved. In the experiments, the addition 
of acetate as a substrate did not lower the effectiveness of propionate elongation with methanol. Using a mixture of acetate and propionate for $n$-valerate production gave similar average $n$-valerate productivities $(45.1 \pm 4.8 \mathrm{mmol} \mathrm{C} / \mathrm{L} /$ day with propionate and acetate, and $46.6 \pm 1.1 \mathrm{mmol} \mathrm{C/L} /$ day with only propionate, at pH 5.8 and $250 \mathrm{mM}$ methanol in the influent). Depending on the desired product spectrum, the decreased selectivity of the $n$-valerate production as a result of the addition of acetate as a substrate (from 58 to $43 \%$ ), could form a disadvantage during $n$-valerate production with multiple substrates.

Two main findings can be used to increase the selectivity and productivity of methanol-based propionate elongation to $n$-valerate. First, the selectivity was improved by lowering the $\mathrm{pH}$ from 5.8 to 5.5 (within the propionate methanol elongation reactor) (Table 2). This increase in selectivity is mainly caused by the decrease of methylotrophic methanogenic activity. Second, the productivity was improved by increasing the methanol concentration in the influent from 250 to $400 \mathrm{mM}$ (Table 2). The methanol concentration prior to increase was a limiting factor for the propionate chain elongation.

By combining these findings that allow for increased selectivity and productivity, the next step in optimizing process performance is to increase the biomass concentration. The use of carrier materials and biomass granulation are efficient strategies to improve the biomass concentration and retention, as shown during other studies [57-59]. Challenges then lie in maintaining the correct selective pressure, as decoupling solid retention time (SRT) from HRT might introduce new problems with methanogen retention in the system. Further optimizing additional factors like $\mathrm{pH}$, volatile fatty acid concentrations, and $\mathrm{CO}_{2}$ availability in the bioreactor could provide methods to increase the selective pressure towards methanol chain elongation, by inhibiting methanogenic activity.

Chen et al. [22] used acidified supermarket waste as a substrate for methanol-based chain elongation at approximately $\mathrm{pH} 6.2$ and a hydraulic retention time of $40 \mathrm{~h}$. Based on the results from the current study, it can be suggested to decrease the $\mathrm{pH}(5.5-5.8)$ and increase the hydraulic retention time (to $95 \mathrm{~h}$ ) to stimulate $n$-valerate from propionate-containing supermarket waste. In addition, the methane production could be decreased by decreasing the $\mathrm{pH}$ to 5.5 . Implementing this knowledge about selective pressure can reduce the costs for $n$-valerate production and create a new open-culture process of biological production of chemicals from biomass and other carbon sources.

\section{Conclusions}

$n$-Valerate was for the first time proven to be produced from propionate and methanol during a continuous methanol-based chain elongation process in an anaerobic open-culture reactor. Acetate formation from methanol occurred at $\mathrm{pH} 5.8$ and decreased at $\mathrm{pH} 5.5$ due to the higher proton concentration and/or the accompanying increased undissociated acids concentration. Methanol consumption did not occur at an HRT of $42 \mathrm{~h}$, whilst an HRT of $95 \mathrm{~h}$ showed to be long enough for methanolconsuming chain elongation processes. The product selectivity for $n$-valerate was increased with $\mathrm{pH}$ lowering from 5.8 to 5.5 during continuous methanol-based propionate elongation. Propionate elongation to $n$-valerate and acetate elongation to iso-butyrate and $n$-butyrate occurred simultaneously in a continuous methanol-based chain elongation reactor with both propionate and acetate present as a chain elongation substrate. The addition of acetate as a substrate did not cause a decrease of the $n$-valerate productivity. The productivity of $n$-valerate was improved by increasing the methanol concentration in the influent from 250 to $400 \mathrm{mM}$ during methanolbased elongation of propionate and acetate. Clostridium luticellarii was suggested to be most abundant during all the steady-states of methanol-based elongation of both propionate and simultaneous elongation of acetate and propionate and is therefore proposed as a main candidate for methanol-based chain elongation.

\section{Methods}

Batch tests and continuous experiments were carried out during this study. A series of batch experiments was carried out in duplo with an initial $\mathrm{pH}$ ranging from 5 to 7.5 (with steps of 0.5 ) to study which $\mathrm{pH}$ range allowed propionate elongation to $n$-valerate. Serum bottles $(250 \mathrm{~mL})$ were filled with $150 \mathrm{~mL}$ medium with $250 \mathrm{mM}$ methanol and $150 \mathrm{mM}$ propionate and $10 \mathrm{ml}$ inoculum from a continuous methanol-based acetate elongation reactor (De Leeuw $\mathrm{K}$, unpublished) and placed in a shaking cabinet at $308 \mathrm{~K}$. The initial headspace consisted of $20 \% \mathrm{CO}_{2}$ and $80 \% \mathrm{~N}_{2}$. An elaborate overview of the medium composition can be found in Additional file 1.

\section{Continuous methanol-based chain elongation}

A 1-L upflow anaerobic bioreactor (UAB) with 0.2-L headspace, as used by Chen et al. [16], was used for continuous methanol-based propionate elongation (Fig. 7). A gas counter was used to measure the amount of produced gas. The reactor content was recirculated with a peristaltic pump (Watson Marlow S CIQ 323, UK) with a velocity of $400 \mathrm{~mL} / \mathrm{min}$. In the recirculation 


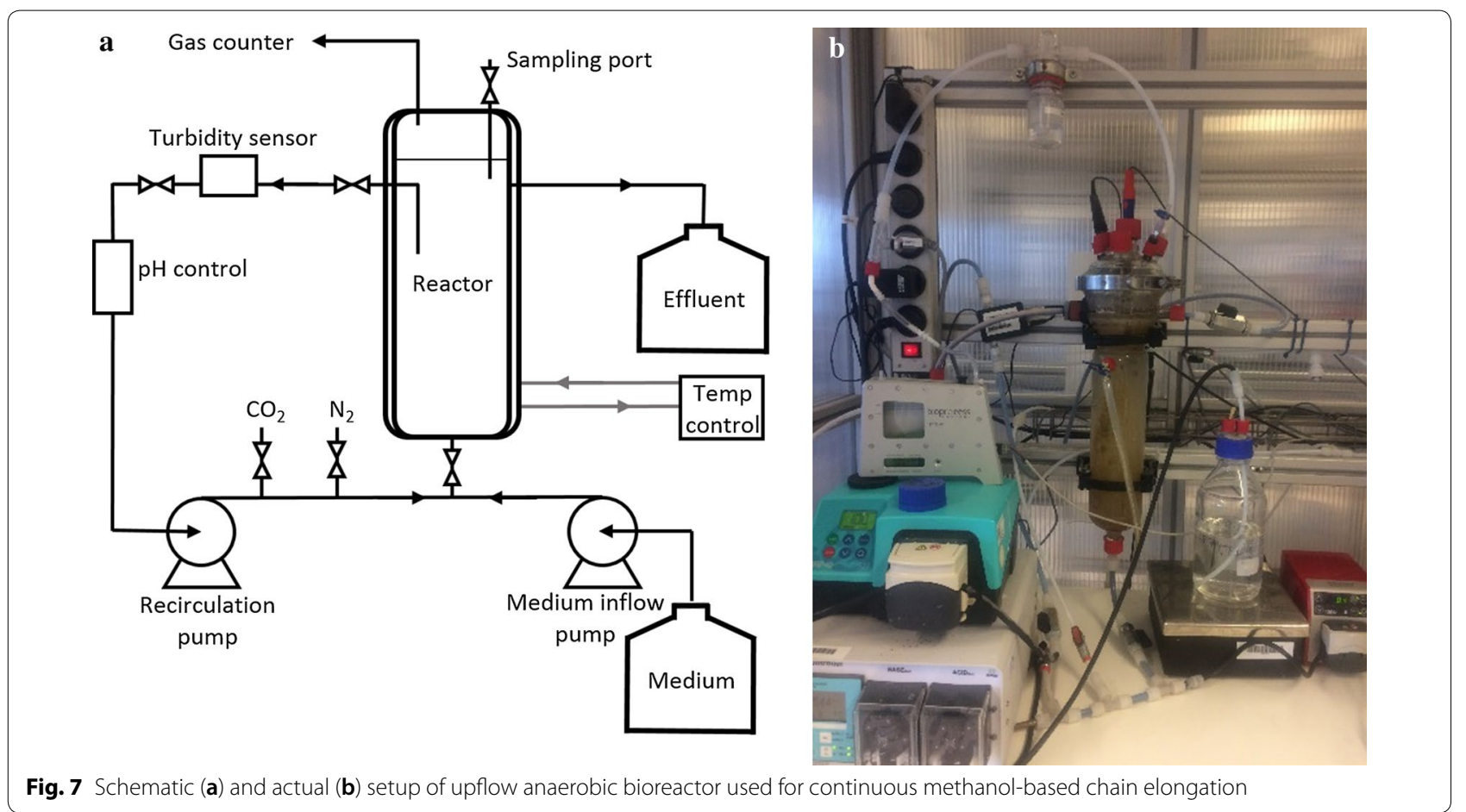

loop, the turbidity and the $\mathrm{pH}$ (Endress Hauser M, Netherlands) were measured. The $\mathrm{pH}$ was maintained constant by automatic addition of potassium hydroxide.

The medium was pumped into the reactor by a peristaltic pump (Watson Marlow IP31, UK), the hydraulic retention time (HRT) could be adjusted by adjusting the pump rate. Carbon dioxide was supplied during the continuous methanol elongation process for acetate formation from methanol and bicarbonate (Table 1R2). The temperature of the reactor was kept at $309 \mathrm{~K}$ using a water bath (Julabo 4, Germany). A medium with $250 \mathrm{mM}$ methanol, $150 \mathrm{mM}$ sodium propionate and $1 \mathrm{~g} / \mathrm{L}$ yeast extract was used. The exact composition of the medium is shown in Additional file 1: Table S1-S8. The medium was stored in a camelbag (MSR Dromedary, $6 \mathrm{~L}$ ) in a fridge at $279 \mathrm{~K}$ that was continuously flushed with nitrogen.

A second reactor was used to study the simultaneous use of acetate and propionate as substrates for methanol-based chain elongation. A 3-L upflow anaerobic bioreactor (UAB) with 0.6-L headspace was used for continuous methanol-based acetate and propionate elongation (Fig. 7a). The recirculation velocity of the reactor content was $300 \mathrm{~mL} / \mathrm{min}$ (Watson Marlow $505 \mathrm{~S}$, UK); the turbidity and $\mathrm{pH}$ were measured in the recirculation loop (Endress Hauser M, Netherlands). The $\mathrm{pH}$ was maintained constant by automatic addition of potassium hydroxide.
The medium ( $250 \mathrm{mM}$ methanol, $75 \mathrm{mM}$ sodium propionate, $75 \mathrm{mM}$ sodium acetate and $1 \mathrm{~g} / \mathrm{L}$ yeast extract) was pumped into the reactor by a peristaltic pump (Watson Marlow IP31, UK). To compare the substrate use, propionate and acetate were added on a 1:1 molar base. The exact composition of the medium is shown in Additional file 1 . The medium was stored in a camelbag in a fridge at $277 \mathrm{~K}$ that was continuously flushed with nitrogen. Carbon dioxide gas was let into the reactor continuously and the temperature of the reactor was kept at $309 \mathrm{~K}$ using a water bath (Julabo F25, Germany).

\section{Analysis}

Three times a week, a gas sample was measured using gas chromatography to analyze the fractions of oxygen, carbon dioxide, methane, nitrogen and hydrogen in the gas phase (Shimadzu GC-2010, Japan). In addition, a liquid sample was taken, from which the concentrations of volatile fatty acids and alcohols (methanol, ethanol, propanol, butanol, pentanol, hexanol, acetate, propionate, $n$-butyrate, iso-butyrate, $n$-valerate, iso-valerate, $n$-caproate, iso-caproate, heptylate and caprylate) were measured using gas chromatography. A liquid sample was also taken from the fresh and old medium when the medium was replaced. The concentration of volatile fatty acids and alcohols of the medium samples was measured as well using gas chromatography (HP5890, USA). The difference between 2-methylbutyrate and 
3-methylbutyrate could not be measured using the available equipment. Therefore, no distinction could be made between the formation of 2- and 3-methylbutyrate during this experiment and both compounds were measured as iso-valerate.

\section{Reactor setting changes}

The setup changes during different phases of the continuous methanol-based propionate elongation process are shown in Table 4. The reactor was inoculated with biomass from the previously mentioned $n$-valerate formation batch experiments at day 0 and day 27. During phase $\mathrm{I}$, decrease of the $n$-valerate formation was observed, the HRT was doubled for phase II. The pH during the $n$-valerate formation phase of the batch experiments was 5.8, so the $\mathrm{pH}$ was lowered to 5.8 to stimulate $n$-valerate formation even further in phase III. Steadystate was reached at day 78 , and after 12 days of steadystate $n$-valerate formation, the $\mathrm{pH}$ of the medium was decreased to 5.5 to inhibit methanogenesis (phase IV). The carbon dioxide supply was changed with changing $\mathrm{pH}$ to maintain a constant bicarbonate concentration during the formation process. The change of the concentration of dissolved $\mathrm{CO}_{2}$ and the $\mathrm{pH}$ in time (Additional file 1: Figure S1) and the calculation of the required $\mathrm{CO}_{2}$ gas flow are shown in Additional file 1 [60, 61].

Table 4 Setup for the different phases of the continuous formation of valerate from propionate and methanol to study the effect of $\mathrm{pH}$ lowering on $\boldsymbol{n}$-valerate formation

\begin{tabular}{lllll}
\hline Phase conditions & Phase I & Phase II & Phase III & Phase IV \\
\hline Hydraulic retention time (h) & 42.3 & 95.2 & 95.2 & 95.2 \\
Phase duration (days) & $0-27$ & $27-43$ & $43-91$ & $91-120$ \\
pH influent & 7.0 & 7.0 & 5.8 & 5.5 \\
pH reactor & $6.4 \pm 0.3$ & $6.3 \pm 0.2$ & 5.8 & 5.5 \\
$\mathrm{CO}_{2}$ supply (mL/min) & 0.18 & 0.18 & 0.36 & 0.40 \\
\hline
\end{tabular}

The changed parameters are indicated in italic

The $\mathrm{pH}$ in the reactor was controlled during phase III and phase IV
The setup changes during different phases of the continuous methanol-based acetate and propionate elongation process are shown in Table 5 . The reactor was inoculated with biomass from the $n$-valerate formation batch experiments at day 0 . No conversions of methanol and acetate were observed during phase $\mathrm{I}$, so the $\mathrm{pH}$ was lowered from 7.0 to 5.8. Carbon dioxide was supplied to the reactor from phase III and onwards. During phase III, the high methanol concentration in the reactor was presumed to be prohibiting microbial activity. Therefore, the reactor was set in batch mode during phase IV, so that the methanol could be consumed and biomass could be accumulated. The hydraulic retention time was increased after the batch phase (during phase V) to prevent washout of $n$-valerate-producing organisms. A steady-state was reached from day 64 to day 71 . In phase VI, the methanol concentration was increased to study whether increase of the concentration of methanol would stimulate the formation of $n$ - and iso-butyrate and $n$-valerate at the same biomass retention rate.

At day 29 (during phase III) and 38 (start of phase IV), the reactor was inoculated with a mix of biomass from the methanol elongation reactor with propionate and a continuous methanol elongation reactor with acetate. The carbon dioxide supply was changed with changing $\mathrm{pH}$ to maintain, a similar theoretically supplied bicarbonate concentration constant during the formation process from phase IV (Additional file 1: Figure S1).

\section{Stoichiometric analysis}

A stoichiometric analysis of the occurred conversions was performed based on the main possible conversions shown in Table 1, combined with the observed changes in the compound composition of the reactors and the obtained carbon and electron balances. The carbon balances per data point are shown in Additional file 1: Figure S3. Further indications of the conversions were given by the measured production of protons and gases (methane, carbon dioxide, hydrogen).

Table 5 Setup for the different phases of the continuous formation of valerate and $n$ - and iso-butyrate from propionate, acetate and methanol to study the effect of methanol increase on $n$ - and iso-butyrate and $n$-valerate formation

\begin{tabular}{|c|c|c|c|c|c|c|}
\hline Phase conditions & Phase I & Phase II & Phase III & Phase IV & Phase V & Phase VI \\
\hline Hydraulic retention time (h) & 46.3 & 42.5 & 45.4 & $\infty$ & 90.5 & 87.8 \\
\hline Phase duration (days) & $0-17$ & $17-20$ & $20-38$ & $38-45$ & $45-71$ & $71-104$ \\
\hline pH influent & 7.0 & 5.8 & 5.8 & 5.8 & 5.8 & 5.8 \\
\hline pH reactor & $6.9 \pm 0.1$ & $6.1 \pm 0.2$ & $5.8 \pm 0.1$ & $5.8 \pm 0.0$ & $5.7 \pm 0.1$ & $5.8 \pm 0.1$ \\
\hline $\mathrm{CO}_{2}$ supply (mL/min) & 0 & 0 & 0.18 & 0.36 & 0.36 & 0.36 \\
\hline Methanol in influent (mM) & 250 & 250 & 250 & - & 250 & 400 \\
\hline
\end{tabular}

The changed parameters are indicated in italic

The $\mathrm{pH}$ in the reactor was controlled during phase II to phase VI. The methanol concentration of the influent was increased from $250 \mathrm{mM}$ to $400 \mathrm{mM}$ in phase VI. The reactor was in batch mode during phase IV 


\section{Microbial community analysis}

To characterize the enrichment of the biomass during propionate methanol chain elongation, samples of both inoculum and steady-state biomass were used for $16 \mathrm{~s}$ rDNA analyses. Inoculum biomass was taken 3 months after taking the last sample from one of the batches that was started at $\mathrm{pH}$ 6.5. Reactor biomass was taken from the propionate methanol chain elongation reactor at day 90 (last day of steady-state), before the next phase was started. Both biomass samples were taken, in duplo, by spinning down $20 \mathrm{~mL}$ in a centrifuge tube and snap-freezing the pellet using liquid hydrogen. From here on, the in duplo taken samples were analyzed separately.

DNA was extracted from the pellets using the Powersoil DNA isolation kit according to their instruction manual. The isolated DNA was then used as the template to amplify the V3-V4 regions of $16 \mathrm{~s}$ rDNA via PCR using the primer sets provided by Takahashi et al. [62]. This allowed simultaneous amplification of bacterial and archaean 16s rDNA. The illumina library generation [62] methods were subsequently used to generate DNA sequence data.

After acquiring rDNA sequence data, a statistical analysis allowed OTU picking, using the SILVA version 128 $16 \mathrm{~S}$ reference database and uclust $[63,64]$. The RDP classifier (version 2.2) [60] was trained with the same SILVA reference database and subsequently used to classify the OTUs. Taxonomic analysis was performed using QIIME software version 1.9.1 [61]. This bioinformatics process was performed on 21 August 2018. From the acquired data, a heat map such as shown in Additional file 1: Table S10 could be made using Microsoft Excel. Opensource software Rstudio v3.5.0 was used to sort the data and create quantitative OTU tables (as in Additional file 1) that belonged to a chosen taxonomic group. This allowed counting the most abundant OTU's that were classified within a single genus. The rDNA sequences of selected abundant OTUs (as in Additional file 1: Table S12) were then used for Megablast to search within the NCBI nucleotide database on 18 April 2019.

\section{Additional file}

Additional file 1. Supplementary information-Continuous $n$-valerate formation from propionate and methanol in an anaerobic chain elongation open-culture bioreactor.

\section{Acknowledgements}

Financial support from the Dutch Technology Foundation NWO and the company Chaincraft B.V. are gratefully acknowledged. The authors would like to thank Sven Warris of Wageningen Plant Research for his support with the bioinformatics and Matthijs van Dam (BSc. student Biotechnology of Wageningen University) for executing preliminary research that led to this study. The authors would also like to thank the entire laboratory and secretarial staff of Environmental Technology of Wageningen University \& Research.

\section{Authors' contributions}

SdS designed and executed experiments, performed analyses, interpreted data, and drafted the manuscript. KdL contributed to experimental design, execution, and data interpretation, performed the microbial analysis and its interpretation, drafted the sections about the microbial analysis and revised the manuscript. CB participated as a co-applicant of the ALWGR.2015.8 project and planning of the study, contributed to experimental design and data interpretation, and revised the manuscript. DS is principal investigator and designer of the ALWGR.2015.8 project, secured project funding, planned the study, contributed to experimental design and data interpretation, and revised the manuscript. All authors read and approved the final manuscript.

\section{Funding}

This work was funded by the Dutch Technology Foundation NWO Groen program which includes support of the company ChainCraft B.V. (Project Number ALWGR.2015.8).

\section{Availability of data and materials}

All data generated or analyzed during this study are included in this published article (and its Additional file). Microbiota raw sequencing data are submitted to the ENA database (https://www.ebi.ac.uk/ena) under accession number PRJEB32281. Raw experimental data is available in the DANS-EASY database (https://doi.org/10.17026/dans-zez-ykrc).

\section{Ethics approval and consent to participate}

Not applicable.

\section{Consent for publication}

Not applicable.

\section{Competing interests}

The authors declare that they have no competing interests.

Received: 16 November 2018 Accepted: 14 May 2019

Published online: 27 May 2019

\section{References}

1. Tilman D. Global environmental impacts of agricultural expansion: the need for sustainable and efficient practices. Proc Natl Acad Sci. 1999;96(11):5995-6000.

2. Foley JA, Ramankutty N, Brauman KA, Cassidy ES, Gerber JS, Johnston M, et al. Solutions for a cultivated planet. Nature. 2011;478(7369):337-42.

3. Ricci A, Allende A, Bolton D, Chemaly M, Davies R, Herman L, et al. Evaluation of the application for a new alternative processing method for animal by-products of Category 3 material (ChainCraft B.V.). EFSA J. 2018;16(6):e05281.

4. Spirito CM, Richter H, Rabaey K, Stams AJ, Angenent LT. Chain elongation in anaerobic reactor microbiomes to recover resources from waste. Curr Opin Biotechnol. 2014;27:115-22.

5. Jourdin L, Raes SMT, Buisman CJN, Strik DPBTB. Critical biofilm growth throughout unmodified carbon felts allows continuous bioelectrochemical chain elongation from $\mathrm{CO}_{2}$ up to caproate at high current density. Front Energy Res. 2018;6:7.

6. Angenent LT, Richter H, Buckel W, Spirito CM, Steinbusch KJ, Plugge $\mathrm{CM}$, et al. Chain elongation with reactor microbiomes: open-culture biotechnology to produce biochemicals. Environ Sci Technol. 2016:50(6):2796-810.

7. Coma M, Vilchez-Vargas R, Roume H, Jauregui R, Pieper DH, Rabaey K. Product diversity linked to substrate usage in chain elongation by mixedculture fermentation. Environ Sci Technol. 2016;50(12):6467-76.

8. Apanel G, Johnson E. Direct methanol fuel cells—ready to go commercial? Fuel Cells Bull. 2004;2004(11):12-7.

9. Kim J, Henao CA, Johnson TA, Dedrick DE, Miller JE, Stechel EB, et al. Methanol production from $\mathrm{CO}_{2}$ using solar-thermal energy: process 
development and techno-economic analysis. Energy Environ Sci. 2011:4(9):3122-32.

10. Leduc S, Lundgren J, Franklin O, Dotzauer E. Location of a biomass based methanol production plant: a dynamic problem in northern Sweden. Appl Energy. 2010;87(1):68-75.

11. Fong W-CF, Wilson RF. Gasification process combined with steam methane reforming to produce syngas suitable for methanol production. Google Patents; 1996.

12. Banerjee R, Ragsdale SW. The many faces of vitamin B12: catalysis by cobalamin-dependent enzymes. Annu Rev Biochem. 2003;72:209-47.

13. LaBelle EV, May HD. Energy efficiency and productivity enhancement of microbial electrosynthesis of acetate. Front Microbiol. 2017;8:756.

14. Gonzalez-Garcia R, McCubbin T, Navone L, Stowers C, Nielsen L, Marcellin E. Microbial propionic acid production. Fermentation. 2017;3(2):21.

15. Bajracharya S, ter Heijne A, Dominguez Benetton X, Vanbroekhoven $K$, Buisman CJ, Strik DP, et al. Carbon dioxide reduction by mixed and pure cultures in microbial electrosynthesis using an assembly of graphite felt and stainless steel as a cathode. Bioresour Technol. 2015;195:14-24.

16. Chen WS, Ye Y, Steinbusch KJJ, Strik DPBTB, Buisman CJN. Methanol as an alternative electron donor in chain elongation for butyrate and caproate formation. Biomass Bioenergy. 2016;93:201-8.

17. Lange JP, Price R, Ayoub PM, Louis J, Petrus L, Clarke L, et al. Valeric biofuels: a platform of cellulosic transportation fuels. Angew Chem Int Ed. 2010;49(26):4479-83.

18. Chan-Thaw CE, Marelli M, Psaro R, Ravasio N, Zaccheria F. New generation biofuels: $\gamma$-valerolactone into valeric esters in one pot. RSC Adv. 2013;3(5):1302-6

19. Luengo JM, García B, Sandoval A, Naharro G, Olivera ER. Bioplastics from microorganisms. Curr Opin Microbiol. 2003;6(3):251-60.

20. Law Jr. CG, Fedkiw PS, Hicks MT. Kolbe electrolysis in a polymer electrolyte membrane reactor. Google Patents; 2001.

21. Moscoviz R, Trably E, Bernet N, Carrère H. The environmental biorefinery: state-of-the-art on the production of hydrogen and value-added biomolecules in mixed-culture fermentation. Green Chem. 2018;20(14):3159-79.

22. Chen WS, Huang S, Strik DPBTB, Buisman CJN. Isobutyrate biosynthesis via methanol chain elongation: converting organic wastes to platform chemicals. J Chem Technol Biotechnol. 2017;92(6):1370-9.

23. Rode L, Genthner BS, Bryant M. Syntrophic association by cocultures of the methanol-and $\mathrm{CO}_{2}-\mathrm{H}_{2}$-utilizing species Eubacterium limosum and pectin-fermenting Lachnospira multiparus during growth in a pectin medium. Appl Environ Microbiol. 1981;42(1):20-2.

24. Lindley N, Loubiere P, Pacaud S, Mariotto C, Goma G. Novel products of the acidogenic fermentation of methanol during growth of Eubacterium limosum in the presence of high concentrations of organic acids. Microbiology. 1987;133(12):3557-63.

25. Agler MT, Wrenn BA, Zinder SH, Angenent LT. Waste to bioproduct conversion with undefined mixed cultures: the carboxylate platform. Trends Biotechnol. 2011;29(2):70-8.

26. Florencio L, Field J, Lettinga G. Importance of cobalt for individual trophic groups in an anaerobic methanol-degrading consortium. Appl Environ Microbiol. 1994;60(1):227-34.

27. Royce LA, Liu P, Stebbins MJ, Hanson BC, Jarboe LR. The damaging effects of short chain fatty acids on Escherichia coli membranes. Appl Microbiol Biotechnol. 2013;97(18):8317-27.

28. Bainotti AE, Yamaguchi $K$, Nakashimada Y, Nishio N. Kinetics and energetics of Acetobacterium sp. in chemostat culture on methanol- $\mathrm{CO}_{2}$.J Ferment Bioeng. 1998;85(2):223-9.

29. Florencio L, Field J, Lettinga G. Substrate competition between methanogens and acetogens during the degradation of methanol in UASB reactors. Water Res. 1995;29(3):915-22.

30. Infantes D, del Campo AG, Villaseñor J, Fernández F. Kinetic model and study of the influence of $\mathrm{pH}$, temperature and undissociated acids on acidogenic fermentation. Biochem Eng J. 2012;66:66-72.

31. Roghair M, Liu Y, Strik D, Weusthuis RA, Bruins ME, Buisman CJN. Development of an effective chain elongation process from acidified food waste and ethanol into n-caproate. Front Bioeng Biotechnol. 2018;6:50.

32. Kouzuma A, Tsutsumi M, Ishii S, Ueno Y, Abe T, Watanabe K. Nonautotrophic methanogens dominate in anaerobic digesters. Sci Rep. 2017;7(1):1510
33. Pacaud S, Loubiere P, Goma G. Methanol metabolism by Eubacterium limosum B2: effects of $\mathrm{pH}$ and carbon dioxide on growth and organic acid production. Curr Microbiol. 1985;12(5):245-50.

34. Conrad R, Klose M, Claus P. Phosphate inhibits acetotrophic methanogenesis on rice roots. Appl Environ Microbiol. 2000;66(2):828-31.

35. Boone DR, Bryant MP. Propionate-degrading bacterium, Syntrophobacter wolinii sp. nov. gen. nov., from methanogenic ecosystems. Appl Environ Microbiol. 1980;40(3):626-32.

36. Dong X, Plugge CM, Stams AJ. Anaerobic degradation of propionate by a mesophilic acetogenic bacterium in coculture and triculture with different methanogens. Appl Environ Microbiol. 1994;60(8):2834-8.

37. Games LM, HayesRobert J, Gunsalus P. Methane-producing bacteria: natural fractionations of the stable carbon isotopes. Geochim Cosmochim Acta. 1978;42(8):1295-7.

38. Breznak JA, Kane MD. Microbial $\mathrm{H}_{2} / \mathrm{CO}_{2}$ acetogenesis in animal guts: nature and nutritional significance. FEMS Microbiol Rev. 1990;7(3-4):309-13.

39. Ames JM, Leod GM. Volatile components of a yeast extract composition. J Food Sci. 1985;50(1):125-31.

40. Allison MJ. Production of branched-chain volatile fatty acids by certain anaerobic bacteria. Appl Environ Microbiol. 1978;35(5):872-7.

41. Florencio L, Nozhevnikova A, Van Langerak A, Stams A, Field J, Lettinga G. Acidophilic degradation of methanol by a methanogenic enrichment culture. FEMS Microbiol Lett. 1993;109(1):1-6.

42. Iino T, Tamaki H, Tamazawa S, Ueno Y, Ohkuma M, Suzuki K-I, et al. Candidatus Methanogranum caenicola: a novel methanogen from the anaerobic digested sludge, and proposal of Methanomassiliicoccaceae fam. nov. and Methanomassiliicoccales ord. nov., for a methanogenic lineage of the class Thermoplasmata. Microbes Environ. 2013:28(2):244-50.

43. Dridi B, Fardeau ML, Ollivier B, Raoult D, Drancourt M. Methanomassiliicoccus /uminyensis gen. nov., sp. nov., a methanogenic archaeon isolated from human faeces. Int J Syst Evol Microbiol. 2012;62(Pt 8):1902-7.

44. Wang Q, Wang CD, Li CH, Li JG, Chen Q, Li YZ. Clostridium luticellarii sp. nov., isolated from a mud cellar used for producing strong aromatic liquors. Int J Syst Evol Microbiol. 2015;65(12):4730-3.

45. Kremp F, Poehlein A, Daniel R, Müller V. Methanol metabolism in the acetogenic bacterium Acetobacterium woodii. Environ Microbiol. 2018;20(12):4369-84.

46. Ragsdale SW, Pierce E. Acetogenesis and the Wood-Ljungdahl pathway of $\mathrm{CO}_{2}$ fixation. Biochim Biophys Acta. 2008;1784(12):1873-98.

47. Haapalainen AM, Meriläinen G, Wierenga RK. The thiolase superfamily: condensing enzymes with diverse reaction specificities. Trends Biochem Sci. 2006;31(1):64-71.

48. Kallscheuer N, Polen T, Bott M, Marienhagen J. Reversal of $\beta$-oxidative pathways for the microbial production of chemicals and polymer building blocks. Metab Eng. 2017:42:33-42.

49. BioRender. Created with BioRender on 25 April 2019. https://biorenderhelp.zendesk.com/hc/en-us/articles/360003904954-Licensing-and-Usage

50. Buckel W, Thauer RK. Energy conservation via electron bifurcating ferredoxin reduction and proton/ $\mathrm{Na}^{+}$translocating ferredoxin oxidation. Biochim Biophys Acta. 2013;1827(2):94-113.

51. Seedorf $H$, Fricke WF, Veith B, Brüggemann $H$, Liesegang $H$, Strittmatter $A$, et al. The genome of Clostridium kluyveri, a strict anaerobe with unique metabolic features. Proc Natl Acad Sci. 2008;105(6):2128-33.

52. Chatellard L, Trably E, Carrère H. The type of carbohydrates specifically selects microbial community structures and fermentation patterns. Bioresour Technol. 2016:221:541-9.

53. Abreu A, Alves J, Pereira M, Sousa D, Alves M. Strategies to suppress hydrogen-consuming microorganisms affect macro and micro scale structure and microbiology of granular sludge. Biotechnol Bioeng. 2011;108(8):1766-75.

54. Albuquerque M, Eiroa M, Torres C, Nunes B, Reis M. Strategies for the development of a side stream process for polyhydroxyalkanoate (PHA) production from sugar cane molasses. J Biotechnol. 2007:130(4):411-21.

55. Marshall CW, Ross DE, Handley KM, Weisenhorn PB, Edirisinghe JN, Henry CS, et al. Metabolic reconstruction and modeling microbial electrosynthesis. Sci Rep. 2017;7(1):8391.

56. Beenackers A, van Swaaij W, editors. Methanol production from biomass. In: Bioenergy 84 proceedings of conference 15-21 June 1984, Goteborg, Sweden Volume I. Bioenergy state of the art. Elsevier Applied Science Publishers; 1984 
57. Fernández I, Vázquez-Padín JR, Mosquera-Corral A, Campos JL, Méndez R. Biofilm and granular systems to improve Anammox biomass retention. Biochem Eng J. 2008;42(3):308-13.

58. Hulshoff Pol LW, de Castro Lopes SI, Lettinga G, Lens PN. Anaerobic sludge granulation. Water Res. 2004;38(6):1376-89.

59. Roghair M, Strik DPBTB, Steinbusch KJJ, Weusthuis RA, Bruins ME, Buisman CJN. Granular sludge formation and characterization in a chain elongation process. Process Biochem. 2016;51(10):1594-8.

60. Sincero AP, Sincero GA. Physical-chemical treatment of water and wastewater. Boca Raton: CRC Press; 2002.

61. Shapley. Dissolved oxygen and carbon dioxide. http://butane.chem.uiuc. edu/pshapley/GenChem1/L23/web-L23.pdf. Accessed 7 Dec 2017.

62. Takahashi S, Tomita J, Nishioka K, Hisada T, Nishijima M. Development of a prokaryotic universal primer for simultaneous analysis of Bacteria and Archaea using next-generation sequencing. PLOS ONE. 2014;9(8):e105592.

63. Quast C, Pruesse E, Yilmaz P, Gerken J, Schweer T, Yarza P, et al. The SILVA ribosomal RNA gene database project: improved data processing and web-based tools. Nucleic Acids Res. 2013;41(Database issue):D590-6.
64. Edgar RC. Search and clustering orders of magnitude faster than BLAST. Bioinformatics. 2010;26(19):2460-1.

65. Wang Q, Garrity GM, Tiedje JM, Cole JR. Naive Bayesian classifier for rapid assignment of rRNA sequences into the new bacterial taxonomy. Appl Environ Microbiol. 2007;73(16):5261-7.

66. Caporaso JG, Kuczynski J, Stombaugh J, Bittinger K, Bushman FD, Costello EK, et al. QIIME allows analysis of high-throughput community sequencing data. Nat Methods. 2010;7(5):335.

67. Hanselmann K. Microbial energetics applied to waste repositories. Experientia. 1991;47(7):645-87.

68. Heijnen J. Bioenergetics of microbial growth. In: Flickinger M, Drew S, editors. Encyclopedia of bioprocess technology: fermentation, biocatalysis and bioseparation. Chichester: Wiley; 1999. p. 267-91.

\section{Publisher's Note}

Springer Nature remains neutral with regard to jurisdictional claims in published maps and institutional affiliations.
Ready to submit your research? Choose BMC and benefit from:

- fast, convenient online submission

- thorough peer review by experienced researchers in your field

- rapid publication on acceptance

- support for research data, including large and complex data types

- gold Open Access which fosters wider collaboration and increased citations

- maximum visibility for your research: over 100M website views per year

At BMC, research is always in progress.

Learn more biomedcentral.com/submissions 